\title{
Visual and somatosensory evoked cortical potentials in multiple sclerosis
}

\author{
W. T R O J A B OR G A NDE. PETERSEN \\ From the Laboratory of Clinical Neurophysiology, Rigshospitalet, University Hospital of Copenhagen, \\ Denmark
}

SUMMARY The diagnostic value of the pattern reversal evoked cortical potential (VEP) and the somatosensory evoked cortical potential (SEP) has been compared in 50 patients with established or suspected multiple sclerosis. A prolonged latency of VEP was found in $96 \%$ of definite cases of multiple sclerosis, $58 \%$ of probable cases, and $20 \%$ of possible cases. A prolonged latency of SEP by stimulation of the median or peroneal nerves or both was found in $86 \%$ of definite cases of multiple sclerosis, $83 \%$ of probable cases, and $50 \%$ of possible cases. When combining the results of all three tests the diagnostic yield increased to $100 \%, 92 \%$, and $50 \%$, respectively.

Since the introduction of the technique for recording cortical evoked potentials stimulated by pattern reversal as a supplementary aid in diagnosing multiple sclerosis, providing objective evidence of even clinically silent lesions by Halliday et al. (1972, 1973b), there have been several attempts to reproduce their positive results (Asselman et al., 1975; Lowitzsch et al., 1976; Mastaglia et al., 1976; Chain et al., 1977; Hennerici et al., 1977; Nilsson, 1978; Shahrokhi et al., 1978). None of these workers have succeeded in obtaining a $96 \%$ incidence of abnormal visual evoked potentials in patients with established or suspected multiple sclerosis as did Halliday et al. (1972, 1973b).

The present report deals with a comparison of results obtained by stimulation of visual and somatosensory pathways in a control group and in patients with established or suspected multiple sclerosis to examine whether the application of more tests can increase the diagnostic yield.

\section{Subjects}

The control group consisted of 36 subjects, aged 25-55 years, without history, signs or symptoms of involvement of the central or peripheral nervous system. The patient group comprised 50 individuals aged $21-64$ years. They were classified in

Address for reprint requests: $\mathrm{Dr}$ W. Trojaborg, Laboratory of Clinical Neurophysiology, Rigshospitalet, University Hospital, Blegdamsvej 9, DK 2100 Copenhagen Ø, Denmark.

Accepted 5 October 1978 three categories according to the criteria of McAlpine et al. (1972): (1) 28 definite cases of multiple sclerosis with signs and symptoms of at least two lesions localised to the CNS with a history of exacerbations and remissions; (2) 12 probable cases of multiple sclerosis with signs and symptoms of two or more lesions but without clear fluctuations; (3) 10 cases with possible multiple sclerosis due to a single characteristic lesion and a history of one or more partial remissions. Eight patients in this group had a slowly progressive spastic paraplegia of unknown origin.

\section{Methods}

VISUAL STIMULATION

The technique of pattern reversal stimulation was similar to that described by Halliday et al. (1972, $1973 \mathrm{a}, \mathrm{b})$. It consisted of back projection of a black and white checkerboard pattern on a semitranslucent screen with a diameter of $500 \mathrm{~mm}$ via a revolving mirror producing a lateral movement of one square width. The movement of the mirror took $3 \mathrm{~ms}$ and occurred each $500 \mathrm{~ms}$. The subjects sat one metre in front of the screen, the stimulating field subtending $32^{\circ}$ at the eye. The individual black or white square was $18 \times 18 \mathrm{~mm}$ and had a luminance of $60 \mathrm{~cd} / \mathrm{m}^{2} \pm 20 \%$ and $3100 \mathrm{~cd} / \mathrm{m}^{2} \pm$ $10 \%$, respectively. The background illumination was less than one lux. The subject was instructed to fixate a small cross in the centre of the screen. Pattern stimulation was presented to each eye in turn, the other eye being covered. 
SOMATOSENSORY STIMULATION

The median and common peroneal nerves were stimulated by a rectangular electric pulse $(0.2 \mathrm{~ms}$ duration) from a double screened stimulator (DISA 14 Eol) via a surface electrode (DISA 13 k62) placed at the wrist and the head of the fibula respectively. The stimulus strength was one and a half times the motor threshold of the abductor pollicis brevis or peroneus longus muscles. Stimuli were presented to the nerves on each side in turn at 3 per second.

\section{RECORDING}

Visual evoked cortical potentials (VEP) were recorded via platinum needle electrodes placed at O1-OZ-O2 corresponding to the International 1020 electrode system, using a reference electrode placed $50 \mathrm{~mm}$ in front of the vertex. Cortical potentials evoked by stimulation of the median and peroneal nerves (SEP) were recorded between needle electrodes placed over the somatosensory hand area and foot area respectively (Giblin, 1964) contralateral to the side of stimulation. The cortical activity was recorded via EMG amplifiers (DISA 15 Col) with a lower limiting frequency of $0.5 \mathrm{~Hz}$ and an upper of $1000 \mathrm{~Hz}$ ( $3 \mathrm{~dB}$ down) and was continuously displayed on an oscilloscope (DISA $15 \mathrm{Hol}$ ). The signals were transferred to a signal averager (Nicolet 1074) which was triggered by the pattern reversal or the nerve stimulator. The sampling time was $400 \mathrm{~ms}$ for visual and $200 \mathrm{~ms}$ for somatosensory evoked potentials. The average response to 128 pattern changes or electrical stimuli was recorded together with a calibration signal via an X-Y pen-plotter (HP 7044A), and then a further 128 stimuli were added to ensure reproducibility.

\section{Results}

\section{NORMAL SUBJECTS}

The pattern reversal VEP had the characteristic major positive component described by Halliday et al. $(1972,1973 \mathrm{~b})$ with a peak latency of $93 \mathrm{~ms}$ (SD $3.8 \mathrm{~ms}, \mathrm{n}=72$ eyes) independent of age (range 25-55 years). In half the subjects the major peak was preceded by a minor positive component with a peak latency of $51 \mathrm{~ms}$ (SD $3.6 \mathrm{~ms}, \mathrm{n}=36$ eyes) similar to that found by Asselman et al. (1975). The mean amplitude of the EP was $14 \mu \mathrm{V}$ (range 6-34 $\mu \mathrm{V})$. The change in latency of the major positive component as a function of the reversal time of the checkerboard pattern was studied in 19 subjects. Figure 1 shows recordings of the movement of the mirror at different speeds from 3 to $50 \mathrm{~ms}$. Figure 2 shows the VEP recorded from one subject at different pattern reversal times. The

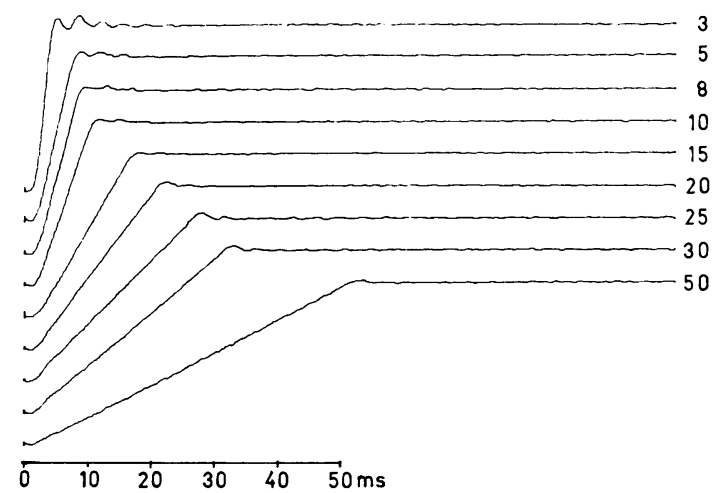

Fig. 1 Recordings of mirror movements used to produce pattern displacement of the checkerboard. The numbers to the right indicate the reversal time in $m s$.

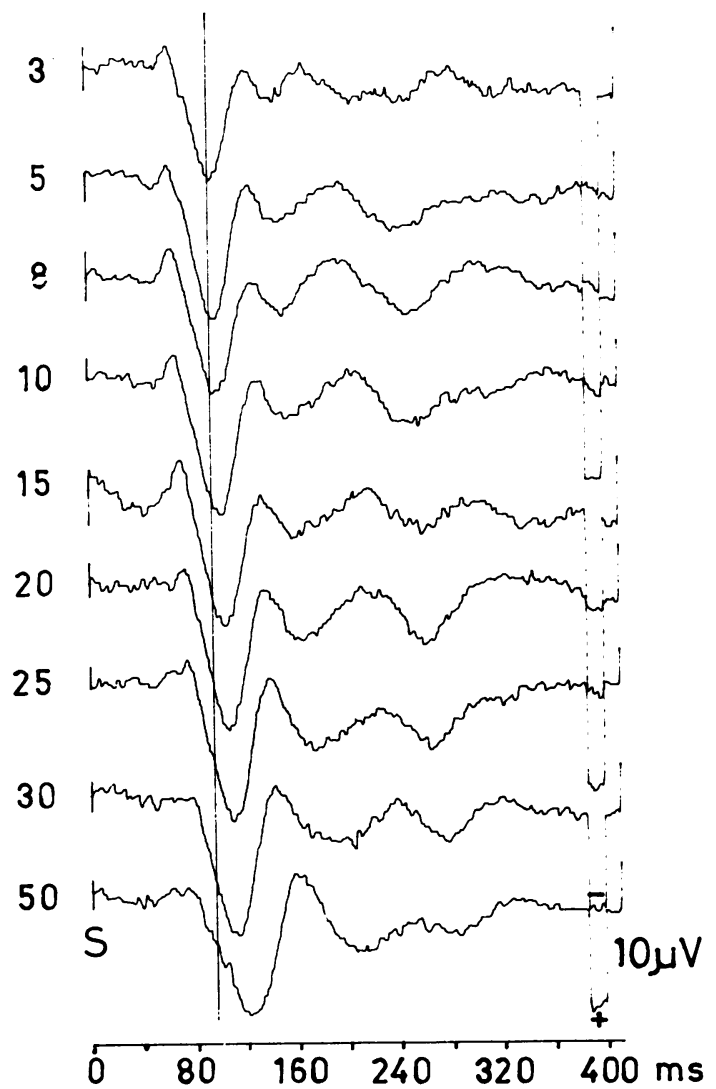

Fig. 2 Recordings from a normal subject of pattern reversal evoked potentials at different speeds of pattern displacement. The numbers to the left indicate the reversal time in $\mathrm{ms}$. The vertical line indicates the latency of the major positive peak when the movement of the mirror took $3 \mathrm{~ms}$. 
latency of the VEP increased from $94 \mathrm{~ms}$ to 125 ms when the displacement of the mirror took 3 and $50 \mathrm{~ms}$ respectively. Figure 3 shows the relation between pattern reversal time and latency of VEP obtained from 19 subjects. The scatter of latencies was smallest when the movement of the mirror took $10 \mathrm{~ms}$ (SD $2.8 \mathrm{~ms}$ ) and largest when it took $50 \mathrm{~ms}$ (SD $5.6 \mathrm{~ms}$ ). The normal values of cortical potentials evoked by peripheral nerve stimulation are shown in Table 1. To accept a finding in the individual patient as abnormal we require a $99 \%$ probability that it does not occur in normal subjects of the same age; the upper $99 \%$ limits being $104 \mathrm{~ms}$ for VEP, $20 \mathrm{~ms}$ and $37 \mathrm{~ms}$ for SEP evoked by stimulating the median and the peroneal nerves respectively.

\section{PATIENTS}

\section{Visual evoked potentials}

There were 20 patients who had suffered an acute attack of retrobulbar neuritis of whom 16 were classified as definite cases of multiple sclerosis and four as probable. Three patients had had an affection of both eyes. A delayed or absent VEP was found in $94 \%$ of the definite cases of multiple sclerosis who had had a history of retrobulbar neuritis compared to $85 \%$ in those who did not (Table 2). All patients with probable multiple sclerosis and a history of retrobulbar neuritis had abnormal responses compared to $26 \%$ of those without retrobulbar neuritis. Thus, all patients but one with a positive history of retrobulbar neuritis had abnormal VEP ( $96 \%)$. Of the 10 possible cases two had an abnormal VEP although they never had had clinical retrobulbar neuritis. Abnormal cortical responses were found on stimulation of both eyes in 23 patients with definite multiple sclerosis $(82 \%)$ although only two had a history of bilateral visual disturbances (Table 3).

Figure 4 gives the distribution of the peak latencies of the major positive component of the VEP from affected and unaffected eyes. No response could be obtained from three affected and blind eyes. The absence of a response from one eye of a patient without retrobulbar neuritis was the result of previous traumatic retinal damage.

\section{Somatosensory evoked potentials}

In all patients but one the median nerve was

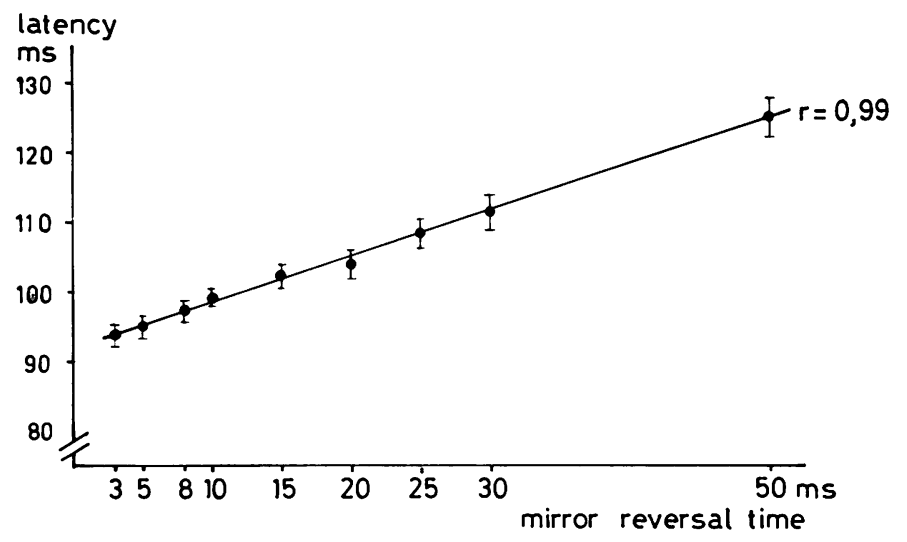

Fig. 3 Relation of pattern reversal time and latency of visual evoked potentials. Each dot represents the mean latency of the major positive component of the $V E P$ from 19 normal subjects. The vertical bars indicate the standard error of the mean. $r=$ correlation coefficient.

Table 1 Latencies (in ms) of components of cerebral response evoked in 17 healthy subjects by stimuli to left and right median and peroneal nerves

\begin{tabular}{|c|c|c|c|c|c|c|c|c|}
\hline Nerve & & Onset & $1^{*}$ & $2 \dagger$ & 3 & 4 & 5 & $\begin{array}{l}\text { Amplitude } \\
(\mu V)\end{array}$ \\
\hline Median & $\begin{array}{l}\text { Mean } \\
\text { SD } \\
\text { Number } \\
\text { Range }\end{array}$ & $\begin{array}{l}16 \\
1.2 \\
34 \\
14-18\end{array}$ & $\begin{array}{l}19 \\
1.8 \\
34 \\
16-22\end{array}$ & $\begin{array}{l}26 \\
2.5 \\
32 \\
22-32\end{array}$ & $\begin{array}{l}32 \\
3.5 \\
32 \\
23-38\end{array}$ & $\begin{array}{l}42 \\
5.2 \\
32 \\
28-56\end{array}$ & $\begin{array}{l}68 \\
9.2 \\
29 \\
52-86\end{array}$ & $\begin{array}{l}8 \\
2 \\
34 \\
4-11\end{array}$ \\
\hline Peroneal & $\begin{array}{l}\text { Mean } \\
\text { SD } \\
\text { Number } \\
\text { Range }\end{array}$ & $\begin{array}{l}27 \\
3.2 \\
34 \\
24-34\end{array}$ & - & $\begin{array}{l}34 \\
3.3 \\
34 \\
30-42\end{array}$ & $\begin{array}{l}44 \\
3.9 \\
34 \\
37-50\end{array}$ & $\begin{array}{l}57 \\
4.8 \\
34 \\
49-66\end{array}$ & $\begin{array}{l}72 \\
7.3 \\
34 \\
60-84\end{array}$ & $\begin{array}{l}5 \\
2.5 \\
34 \\
2-11\end{array}$ \\
\hline
\end{tabular}

*Uneven numbers refer to negative going peaks.

†Even numbers to positive going peaks (Desmedt, 1971). 
Table 2 Incidence (\%) of abnormal visual (VEP) and somatosensory (SEP) evoked potentials in patients with established or suspected multiple sclerosis

\begin{tabular}{|c|c|c|c|c|c|c|c|c|}
\hline \multirow[t]{5}{*}{ Classification of $M S$} & \multicolumn{4}{|l|}{$V E P$} & \multicolumn{4}{|c|}{$S E P M_{+} P$} \\
\hline & \multicolumn{4}{|l|}{$a b n / n \dagger$} & \multicolumn{4}{|l|}{$a b n / n_{+}^{+}$} \\
\hline & \multicolumn{4}{|c|}{ Retrobulbar neuritis } & \multicolumn{4}{|c|}{ Sensory impairment* } \\
\hline & \multicolumn{2}{|l|}{$\therefore$} & \multicolumn{2}{|l|}{-} & \multicolumn{2}{|l|}{ • } & \multicolumn{2}{|l|}{$\cdots$} \\
\hline & Number & $\%$ & Number & $\%$ & Number & $\%$ & Number & $\%$ \\
\hline $\begin{array}{l}\text { Definite (28) } \\
\text { Probable (12) } \\
\text { Possible (10) }\end{array}$ & $\begin{array}{l}17 / 18 \\
5 / 5 \\
0\end{array}$ & $\begin{array}{c}94 \\
100 \\
0\end{array}$ & $\begin{array}{r}33 / 38 \\
5 / 19 \\
2 / 20\end{array}$ & $\begin{array}{l}85 \\
26 \\
10\end{array}$ & $\begin{array}{r}34 / 42 \\
16 / 19 \\
7 / 10\end{array}$ & $\begin{array}{l}88 \\
84 \\
70\end{array}$ & $\begin{array}{r}24 / 57 \\
11 / 27 \\
6 / 30\end{array}$ & $\begin{array}{l}42 \\
41 \\
20\end{array}$ \\
\hline Total (50) & $22 / 23$ & 96 & $40 / 77$ & 52 & $60 / 71$ & 85 & $41 / 114$ & 36 \\
\hline
\end{tabular}

$\mathbf{M}+\mathbf{P}=$ median and peroneal nerves.

*Vibration or position sense or both.

$\dagger$ Number of eyes stimulated.

${ }_{\ddagger}$ Number of hands and legs stimulated.

Table 3 Number of patients with established or suspected multiple sclerosis with delayed or absent visual (VEP) or somatosensory (SEP) evoked potentials

\begin{tabular}{|c|c|c|c|c|c|}
\hline \multirow{2}{*}{$\begin{array}{l}\text { Classification } \\
\text { of } M S\end{array}$} & \multirow[t]{2}{*}{$E P$} & \multicolumn{2}{|c|}{ Abnormality } & \multicolumn{2}{|l|}{ Total } \\
\hline & & Unilateral & Bilateral & Number & $\%$ \\
\hline Definite (28) & $\begin{array}{l}\text { VEP } \\
\text { SEP }_{M}{ }^{*} \\
\text { SEP }_{P}\end{array}$ & $\begin{array}{l}4 \\
9 \\
3\end{array}$ & $\begin{array}{r}23 \\
9 \\
15\end{array}$ & $\begin{array}{l}27 \\
18 \\
18\end{array}$ & $\begin{array}{l}96 \\
64 \\
82\end{array}$ \\
\hline Probable (12) & $\begin{array}{l}\text { VEP } \\
\text { SEP }_{M} \\
\text { SEP }_{P}\end{array}$ & $\begin{array}{l}4 \\
3 \\
3\end{array}$ & $\begin{array}{l}3 \\
5 \\
6\end{array}$ & $\begin{array}{l}7 \\
8 \\
9\end{array}$ & $\begin{array}{l}58 \\
67 \\
75\end{array}$ \\
\hline Possible (10) & $\begin{array}{l}\text { VEP } \\
\text { SEP }_{M} \\
\text { SEPP }_{P}\end{array}$ & $\begin{array}{l}2 \\
3 \\
2\end{array}$ & $\begin{array}{l}0 \\
1 \\
3\end{array}$ & $\begin{array}{l}2 \\
4 \\
5\end{array}$ & $\begin{array}{l}20 \\
40 \\
50\end{array}$ \\
\hline
\end{tabular}

*Examined in 22 of the 28 patients, $\mathrm{M}=$ median nerve, $\mathrm{P}=$ peroneal nerve.

stimulated on both sides as was the peroneal nerve in 43 patients. Thus the analysis included 185 cortical responses. The results are shown in Table 2 in relation to whether or not vibration and posi- tion sense or both were impaired. Clinically these senses were impaired or absent in 71 of $185 \mathrm{ex}$ amined extremities $(38 \%)$. Electrophysiologically, however, abnormalities were encountered in 101 $(55 \%)$. Delayed or absent cortical responses were found in $88 \%$ of cases with definite multiple sclerosis in whom vibration or position sense or both were impaired compared to $42 \%$ in those with normal sensibility. Similar changes were found among cases classified as probable and possible multiple sclerosis.

Abnormalities were found bilaterally in half theo patients when stimulating the median nerves and? in three-quarters when stimulating the peroneal nerves, although only one-third and half of the patients had sensory disturbances corresponding to the upper and lower extremities respectively. Among the definite cases of multiple sclerosis a positive result was found more often when stimulating the peroneal than the median nerve $(82 \%$ and $64 \%$ respectively). In the two other categories

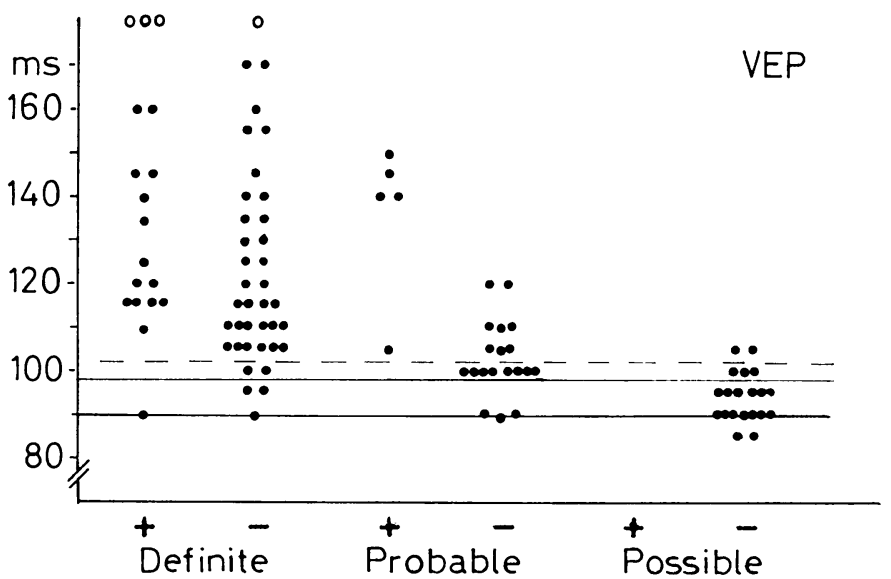

Fig. 4 Latencies of visual pattern reversal evoked potentials from both eyes in 50 patients with established or suspected multiple sclerosis. $+=$ history of retrobulbar neuritis, $-=$ no history of retrobulbar neuritis. Open circles indicate absence of cortical response. The thick horizontal line indicates the normal value, the thin and stippled lines the $95 \%$ and $99 \%$ upper confidence limits respectively. 

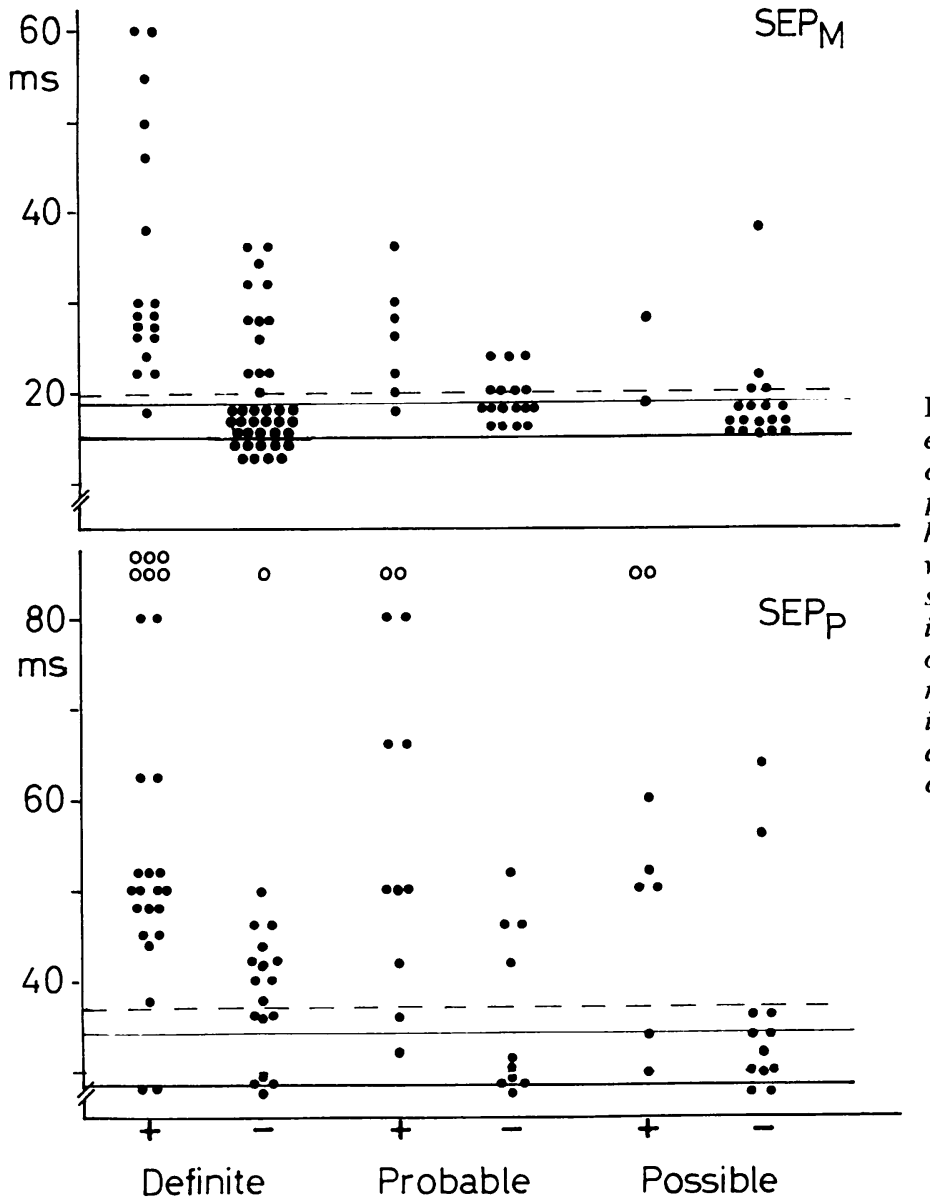

Fig. 5 Latencies of somatosensory evoked cortical potentials by stimulation of right and left median $\left(S E P_{\mathrm{M}}\right)$ and peroneal $\left(S E P_{P}\right)$ nerves at the wrist and head of fibula respectively in 50 patients with established or suspected multiple sclerosis. $+=$ impairment,$-=$ no impairment of vibration or position sense or both. Open circles = absence of cortical responses. The horizontal thick lines indicate the normal mean value, the thin and stippled lines the $95 \%$ and $99 \%$ upper confidence limits respectively. of patients the incidence of abnormal responses was about the same whether the median or the peroneal nerves were stimulated.

The individual values of latencies to the onset of the SEP are shown in Fig. 5. Some examples of SEPs are shown in Fig. 6. The most common abnormality was the absence of the first negative peak as described by Namerow (1968) and Tamuro and Kuroiwa (1972).

Both visual and somatosensory evoked potentials The diagnostic yield when both techniques were applied is shown in Table 4. All patients with definite multiple sclerosis had abnormal cortical potentials to either visual or somatosensory stimulation. Among the probable cases of multiple sclerosis the diagnostic yield increased to $92 \%$ from $58 \%$ and $83 \%$ when only VEP and SEP were used respectively. Two of the 10 patients with possible multiple sclerosis had abnormal VEP and SEP,
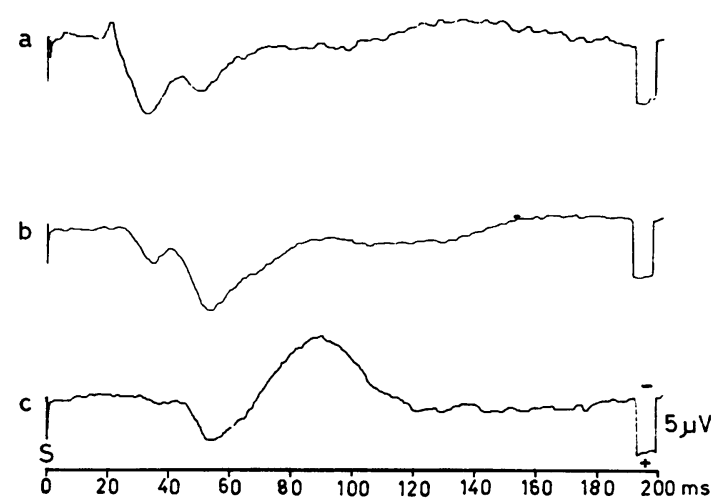

Fig. 6 Somatosensory cortical potentials evoked by stimulation of the median nerve at wrist. (a) Normal response from a 43 year old woman with probable multiple sclerosis. (b) Delayed response from a 42 year old woman with definite multiple sclerosis. (c) Delayed response from a 46 year old man with spastic paraplegia, grouped as possible multiple sclerosis. Note absence of N1 and the delay of P2 in (b) and (c). 
Table 4 Number of patients with established or suspected multiple sclerosis with delayed or absent visual (VEP) and somatosensory (SEP) evoked potentials or both

\begin{tabular}{|c|c|c|c|c|c|c|}
\hline \multirow{2}{*}{$\begin{array}{l}\text { Classification } \\
\text { of } M S \\
\end{array}$} & \multicolumn{2}{|l|}{$V E P$} & \multicolumn{2}{|c|}{$\left.S E P M_{+} P^{*}\right)$} & \multicolumn{2}{|c|}{$\begin{array}{l}V E P+ \\
S E P M_{+} P\end{array}$} \\
\hline & Number & $\%$ & Number & $\%$ & Number & $\%$ \\
\hline Definite (28) & 27 & 96 & 19 & 86 & 28 & 100 \\
\hline Probable (12) & 7 & 58 & 10 & 83 & 11 & 92 \\
\hline Possible (10) & 2 & 20 & 5 & 50 & 5 & 50 \\
\hline
\end{tabular}

$\mathbf{M}+\mathbf{P}$ evoked by stimulating the median and the peroneal nerves respectively.

*Examined in 22 of the 28 patients with definite multiple sclerosis.

and a further three patients had abnormal SEP to both median and peroneal nerve stimulation.

\section{Discussion}

FINDINGS IN NORMAL SUBJECTS

The latency, amplitude, and shape of cortical potentials evoked by visual stimulation depend on a number of factors such as the intensity of the light, its wave length and character (patterned or unpatterned), the frequency of stimulation and, when patterned, the size of the pattern (Regan, 1972, 1975; Halliday et al., 1973a). Moreover, with pattern reversal stimulation, the latency of the VEP depends on the speed of pattern displacement. Using the method of Halliday et al. $(1972,1973 \mathrm{~b})$ we found that the latency increased linearly with increasing pattern reversal time from 3 to $50 \mathrm{~ms}$; the increase in latency being $0.6 \mathrm{~ms}$ per millisecond increase in reversal time. Thus, the differences in mean latency of pattern reversal VEP between different studies can be accounted for by variations in technique. It is, therefore, necessary to use a standardised method and to establish normal values for comparison with findings in patients.

As to the mean peak latencies of somatosensory evoked potentials there is better agreement between different studies. The latency is not affected by variation of stimulus intensity from a level just above sensory threshold to the maximal level tolerated, whereas the amplitude, especially of the early components of the SEP, increases with increasing stimulus intensity (Hume and Cant, 1978).

\section{FINDINGS IN PATIENTS}

Among 50 patients with established or suspected multiple sclerosis we found, in agreement with Lowitzsch et al. (1976), delayed or absent cortical responses to pattern reversal stimulation in $72 \%$ in contrast to the $96 \%$ found by Halliday et al. $(1972,1973 b)$. This very high overall proportion of abnormalities seems not to have been reproduced so far. In different reports the incidence of abnormalities varies from $50 \%$ to $75 \%$ (Asselman et al., 1975; Mastaglia et al., 1976; Hennerici et al., 1977; Matthews et al., 1977; Shahrokhi et al., 1978; Nilsson, 1978).

In patients with multiple sclerosis established on other grounds we found, as Halliday et al. (1972, 1973b), abnormal VEP in $97 \%$ compared to 79 $88 \%$ by others (Asselman et al., 1975; Lowitzsch et al., 1976; Hennerici et al., 1977; Matthews et al., 1977; Shahrokhi et al., 1978; Nilsson, 1978). A similar high proportion of abnormal responses to somatosensory stimulation was found in the present study, and when combining the results of these tests with those of pattern reversal stimulation abnormalities were found in all the definite cases of multiple sclerosis.

It is, however, of more interest that among patients classified as probable cases, in whom about half had delayed response to visual stimulation, the diagnostic yield increased to $92 \%$ when combined with the results of somatosensory stimulation. That Mastaglia et al. (1977) obtained an increase in the proportion of abnormalities from 54 to $64 \%$ can only be explained by the fact that they recorded cortical potentials to stimulation of the median nerve alone whereas we in addition recorded cor-tical potentials evoked by stimulation of the peroneal nerve.

The incidence of delayed VEP among patients with possible multiple sclerosis varies considerably between different reports. Halliday et al. (1973b) found abnormal VEP in 11 of 13 such cases whereas Asselman et al. (1975) did so in only three of 14 patients. Other reports indicate incidence of abnormality from 33-70\% (Lowitzsch et al., 1976; Chain et al., 1977; Matthews et al., 1977). Among our 10 cases of possible multiple sclerosis, two had delayed VEP and three had delayed SEP - that is, in half the cases the electrophysiological investigation supported the clinical suspicion.

The patients with chronic progressive spastic paraplegia represent a special problem. They are usually classified as possible cases of multiple sclerosis when other causes have been excluded. A clinical follow-up of such patients has shown that one-third develop further signs and symptoms suggestive of multiple sclerosis (Marshall, 1955; Hübbe and Mouritzen, 1973). Similarly, at necropsy, Marshall (1955) found that 12 of 35 cases had multiple sclerosis of which half were diagnosed before death, while the remaining had either medullary compression, vascular or osseous abnormalities causing the paraplegia. In five of our eight cases of chronic paraplegia we found delayed 
SEP, but no abnormality of VEP. However, Halliday et al. (1973b) found delayed VEP in five of 13 patients with spastic paraplegia, and Matthews et al. (1977) found abnormal VEP in four of their nine patients. The incidence of abnormal VEP is lower in patients with chronic progressive paraplegia than in definite and probable cases of multiple sclerosis but the proportion of abnormality is similar to what could be expected from necropsy findings. It may, therefore, be that the paraplegic patients with normal evoked potentials do not have multiple sclerosis.

The value of EP methods in the early diagnosis of multiple sclerosis-when there has been only one transient episode of neurological symptoms outside the visual system-is not evident from this nor from other studies. Halliday et al. (1973b) found normal VEP in six patients with a single attack suggesting brainstem involvement, whereas Asselman et al. (1975) described delayed VEP in six of 13 patients with similiar symptoms. Matthews et al. (1977) examined 39 patients with a single acute episode resembling multiple sclerosis and found delayed VEP in only two. However, a follow-up of these two patients confirmed the clinical suspicion as they entered into one of the diagnostic categories of multiple sclerosis. The fate of the remaining patients is unknown.

It has been shown that recording of brainstem evoked responses by auditory stimulation can be helpful in the diagnosis of multiple sclerosis (Robinson and Rudge, 1977; Stockard et al., 1977), but it is not known whether this method leads to positive results when the other evoked potential techniques fail to reveal abnormalities.

It is promising to know that a refinement of pattern reversal stimulation can increase the diagnostic yield especially among the cases of possible multiple sclerosis. Thus, Hennerici et al. (1977) found that using a small white square subtending $45^{\prime}$ instead of the conventional $20^{\circ}$ increased the incidence of abnormal VEP from $43 \%$ to $78 \%$. Similar results were obtained by Nilsson (1978) using light-emitting diodes of red colour to produce a pattern reversal.

The somatosensory cortical evoked potential has not been widely accepted as a tool in the diagnosis of multiple sclerosis. Namerow (1968) recorded SEP from 58 hands of 40 patients with definite multiple sclerosis and found abnormal responses from 43 hands $(74 \%)$. In smaller series of cases of definite multiple sclerosis studied by Tamuro and Kuroiwa $(1972, \mathrm{n}=16)$ and Mastaglia et al. $(1977, \mathrm{n}=14)$ there were abnormal responses in $50 \%$. We found a much higher incidence of abnormality in patients with established multiple sclerosis $(86 \%)$ when combining the results obtained by stimulating the median and peroneal nerves - that is, nearly the same proportion of abnormality as when using VEP. Abnormal SEPs were found more frequently than abnormal VEPs in our cases of probable and possible multiple sclerosis. Whether this is merely an incidental finding awaits further confirmation.

Our findings that patients with impaired vibration and position sense more often have delayed SEP than those with intact sensation are in agreement with previous reports (Halliday and Wakefield, 1963; Giblin, 1964; Larsson et al., 1966; Namerow, 1968), and thus support the suggestion that the posterior columns are the main pathway for the SEP (Larsson et al., 1966).

This investigation was supported by the Danish Medical Research Council.

\section{References}

Asselman, P., Chadwick, D. W., and Marsden, C. D. (1975). Visual evoked responses in the diagnosis and management of patients suspected of multiple sclerosis. Brain, 98, 261-282.

Chain, F., Mallecourt, J., Leblanc, M., and Lhermitte, F. (1977). Apport de l'enregistrement des potentiels évoqués visuels au diagnostic de la sclérose en plaques. Revue Neurologique, 133, 81-88.

Desmedt, J. E. (1971). Somatosensory cerebral evoked potentials in man. In Handbook of Electroencephalography and Clinical Neurophysiology, vol. 9, pp. 55-82. Edited by A. Rémond. Elsevier: Amsterdam.

Giblin, D. R. (1964). Somatosensory evoked potentials in healthy subjects and in patients with lesions of the nervous system. Annals of the New York Academy of Sciences, 112, 93-142.

Halliday, A. M., and Wakefield, G. S. (1963). Cerebral evoked potentials in patients with dissociated sensory loss. Journal of Neurology, Neurosurgery, and Psychiatry, 26, 211-219.

Halliday, A. M., McDonald, W. I., and Mushin, J. (1972). Delayed visual response in optic neuritis. Lancet, 1, 982-985.

Halliday, A. M., McDonald, W. I., and Mushin, J. (1973a). Delayed pattern-evoked responses in optic neuritis in relation to visual acuity. Transactions of the Ophthalmological Society of the United Kingdom, 93, 315-325.

Halliday, A. M., McDonald, W. I., and Mushin, J. (1973b). Visual evoked response in diagnosis of multiple sclerosis. British Medical Journal, 4, 661664.

Hennerici, M., Wenzel, D., and Freund, H.-J. (1977). The comparison of small-sized rectangle and checkerboard stimulation for the evaluation of delayed visual evoked responses in patients suspected of multiple sclerosis. Brain, 100, 119-136.

Hume, A. L., and Cant, B. R. (1978). Conduction time in central somatosensory pathways in man. 
Electroencephalography and Clinical Neurophysiology, 45, 361-375.

Hübbe, P., and Mouritzen, A. D. (1973). Spastic paraplegia of unknown origin. A follow-up of 32 patients. Acta Neurologica Scandinavica, 49, 536542.

Larsson, S. J., Sances, A., and Christenson, P. C. (1966). Evoked somatosensory potentials in man. Archives of Neurology (Chicago), 15, 88-93.

Lowitzsch, K., Kuhnt, U., Sakmann, Ch., Maurer, K., Hopf, H. C. Schott D. and Thäter K. (1976). Visual pattern evoked responses and blink reflexes in assessment of MS diagnosis. A clinical study of 135 multiple sclerosis patients. Journal of Neurology, 213, 17-32.

Marshall, J. (1955). Spastic paraplegia of middle age. A clinico-pathological study. Lancet, 1, 643-645.

Mastaglia, F. L., Black, J. L., and Collin, D. W. K. (1976). Visual and spinal evoked potentials in diagnosis of multiple sclerosis. British Medical Journal, 2, 732-733.

Mastaglia, F. L., Black, J. L., Cala, L. A., and Collins, D. W. K. (1977). Evoked potentials, saccadic velocities, and computerised tomography in diagnosis of multiple sclerosis. British Medical Journal, 1, 1315-1317.

Matthews, W. B., Small, D. G., Small, M., and Pountney, E. (1977). Pattern reversal evoked visual potential in the diagnosis of multiple sclerosis. Journal of Neurology, Neurosurgery, and Psychiatry, 40, 1009-1014.
McAlpine, D., Lumsden, C. E., and Acheson, E. D. (1972). Multiple Sclerosis. A reappraisal. Churchill Livinstone: Edinburgh and London.

Namerow, N. S. (1968). Somatosensory evoked responses in multiple sclerosis patients with varying sensory loss. Neurology, 18, 1197-1204.

Nilsson, B. Y., (1978). Visual evoked responses in multiple sclerosis: comparison of two methods for pattern reversal. Journal of Neurology, Neurosurgery, and Psychiatry, 41, 499-504.

Regan, D. (1972). Evoked Potentials in Psychology, Sensory Physiology and Clinical Medicine. Chapman and Hall: London.

Regan, D. (1975). Recent advances in electrical recording from the brain (Review). Nature, 253, 401-407.

Robinson, K., and Rudge, P. (1977). Abnormalities of the auditory evoked potentials in patients with multiple sclerosis. Brain, 100, 19-40.

Shahrokhi, F., Chiappa, K. H., and Young, R. R. (1978). Pattern shift visual evoked responses. Two hundred patients with optic neuritis and/or multiple sclerosis. Archives of Neurology (Chicago), 35, 6571.

Stockard, J., Stockard, S. E., and Sharbrough, F. W. (1977). Detection and localization of occult lesions with brainstem auditory responses. Mayo Clinic Proceedings, 52, 761-769.

Tamura, K., and Kuroiwa, Y. (1972). Somatosensory evoked responses in patients with multiple sclerosis. Folia Psychiatrica et Neurologica Japonica, 26, 269274. 